\title{
Development of a synchrotron biaxial tensile device for in-situ characterization of thin films mechanical response
}

G. Geandier, ${ }^{1,2,3}$ D. Thiaudière, ${ }^{2}$ R. N. Randriamazaoro, ${ }^{3}$ R. Chiron, ${ }^{3}$ S. Djaziri, ${ }^{1}$ B. Lamongie, ${ }^{1}$ Y. Diot, ${ }^{1}$ E. Le Bourhis, ${ }^{1 a)}$ P. O. Renault,${ }^{1}$ P. Goudeau, ${ }^{1}$ A. Bouaffad, ${ }^{2}$ O. Castelnau, ${ }^{3}$ D. Faurie, ${ }^{3}$ F. Hild ${ }^{4}$

${ }^{1}$ Institut Pprime - département PMM, UPR 3346 CNRS - Université de Poitiers - ENSMA, SP2MI - Teleport 2 - Boulevard Marie et Pierre Curie, BP 30179 - 86962 FUTUROSCOPE Chasseneuil Cedex - France

${ }^{2}$ Synchrotron SOLEIL, L'Orme des Merisiers, BP 48, 91192 Gif sur Yvette, France

${ }^{3}$ LPMTM, UPR 9001 CNRS - Université Paris-Nord, 93430 Villetaneuse, France,

${ }^{4}$ LMT Cachan, 61 Avenue du Président Wilson 94235 CACHAN Cedex

a) Corresponding author: Tel. +33549496658 - Fax +33 549496693

Eric.le.bourhis@univ-poitiers.fr

Keywords: Synchrotron x-ray diffraction, bi-axial tensile set-up, thin film mechanical properties 


\begin{abstract}
We have developed on the DIFFABS-SOLEIL beamline a biaxial tensile machine working in synchrotron environment for in-situ diffraction characterization of thin polycrystalline films mechanical response. The machine has been designed to test compliant substrates coated by the studied films under controlled applied strain field. Technological challenges comprise the sample design including fixation of the substrate ends, the related generation of a uniform strain field in the studied (central) volume, the operations from the beamline pilot. Preliminary tests on $150 \mathrm{~nm}$ thick W films deposited onto polyimide cruciform substrates are presented. The obtained results for applied strains using x-ray diffraction and digital image correlation methods clearly show the full potentialities of this new set-up.
\end{abstract}

Keywords: Thin films, biaxial tensile setup, in situ, x-ray diffraction, optical measurements. 


\section{INTRODUCTION}

Understanding the mechanical behavior of nano-structured thin films in relation to their microstructure, in particular to the grain size, is of utmost importance for the development of technological applications. ${ }^{1}$ In fact, for nanometer length scale, mechanical properties are significantly altered. ${ }^{2-6}$ The processes responsible for these changes are not fully understood yet and are believed to be caused by an increase in grain-surface and grain-boundary volumes, which become dominant over the bulk at the nanoscale. In a film, changes are further caused by boundary conditions at the free surface and interface with the substrate which become non negligible for small thicknesses. ${ }^{1,7}$ The study of elastic behavior can be addressed with $\mathrm{x}$-ray diffraction that allows capturing with high precision the elastic strains. ${ }^{8,9}$ In that way, some in situ tensile tester have been developed to estimate components of applied strain by measuring diffraction line shifts with conventional laboratory sources. ${ }^{10,11}$ More recently, high energy synchrotron $\mathrm{x}$-rays have been used to interrogate samples in transmission to determine lattice strains including strains produced during in-situ loading. ${ }^{12-14}$ High intensity synchrotron $\mathrm{x}-$ rays allow for characterizing small volume of material in an acceptable time schedule. Hence, supported thin films mechanical response has been characterized experimentally in-situ by synchrotron $\mathrm{x}$-ray diffraction ${ }^{15,16}$ while having in view their microstructure. This is particularly important when the films are formed by elastically anisotropic crystallites. In that case, when the crystallites are not randomly distributed (for instance in the presence of fiber texture) the elastic film response is expected to be macroscopically anisotropic. ${ }^{17}$ The tests are generally carried out under uniaxial loading on the composite film/substrate, the films being stressed biaxially because of the Poisson ratio's mismatch between the film and the supporting substrate ${ }^{15}$ or between the different sub-layers. ${ }^{18}$ The transversal component of stress is then controlled by the deposited film properties with a related width shown in Figure 1. 
Flexible and stretchable electronics are being developed for diverse applications, including electronic textiles, paper-like displays, and sensitive skins. ${ }^{19}$ Mechanical failure of metallic stiff thin films attached to a compliant substrate poses a significant challenge in the development of such integrated structures. During operation, such electronic devices can be stretched or bent, while the deformation conditions can be much more complicated than the one obtained from a uniaxial or quasi-uniaxial tensile test. It has been recognized that limiting the evaluation of a material characteristic to uniaxial coupon test can lead to a misrepresentation of the behavior of a material in an engineering structure. ${ }^{20}$ Using more realistic loading during the test leads to a more accurate representation of the expected behavior of the structure in-service. Aiming to mimic a wide range of deformation of a film attached to compliant substrate, it is of utmost importance to control both longitudinal and transversal stress components.

The exploration of the thin film stress diagram has then been carried out step by step. Supported films tests have been performed uniaxially until recently, the supporting substrate being mostly a polyimide. ${ }^{15,16}$ Self supporting films could be tested either uniaxially or equibiaxially by bulging the fabricated membrane. ${ }^{21,22} \mathrm{~A}$ question arises as to how the preparation of the membrane may affect the film response while information is demanded on supported films as employed in applications. With a different approach, Eve et al. ${ }^{23}$ developed a ring on ring device to test equibiaxially the fatigue of coated PC and PMMA substrates. The device was designed to explore both compression and traction in equibiaxial stress states (diagonal line on the diagram of Fig. 1). Thermal annealing of film/substrate composite can also be used to induce equibiaxial stress state in the thin films because of the mismatch of thermal expansion coefficient between the thin film and the substrate. ${ }^{24,25}$ However, latter technique has to be used with care because of the recrystallisation phenomena (grain growth) and phase transformation, and moreover, the accessible range of stress state is limited. So far, 
as illustrated in Fig. 1 diagram, only small regions of the loading map could be explored. Therefore, we decided to develop a biaxial loading machine working in synchrotron environment allowing for applying in plane normal forces to supported films and hence explore the overall dashed area of Figure 1.

We report the design of both the machine and cruciform specimens and show biaxial strain results obtained for supported thin $\mathrm{W}$ films. This article describes the in-situ mechanical biaxial loading system to be positioned at the goniometer center in the DiffAbs experimental station at the SOLEIL synchrotron source. In the following sections, the biaxial tensile module is described. A finite element analysis on the cruciform substrate is presented and some experimental results on model W films are used to demonstrate the utility of the system.

\section{BIAXIAL TENSILE MACHINE DESIGN}

The design of the biaxial tensile machine was governed by the following constraints and objectives:

-the sample dimensions, experimental configuration, and x-ray energy must be such that $\mathrm{x}$ rays interrogate a significant volume fraction of crystalline thin films. In the case of thin films grazing angles measurements should be accessible.

-the sample is interrogated while subjected to a biaxial tensile stress state at progressively higher applied loads. It is imperative that the specimen is well aligned within loading grips and do not move during loading.

-Interesting mechanical phenomena involve multiphase materials. One of the intrinsic advantages of diffraction techniques is that lattice strains of each crystalline phase can be measured independently with high accuracy. Moreover, correlation between lattice strains and macroscopic strains measured thanks to an optical method for instance, is important information concerning the elastic grains interaction in anisotropic polycrystalline material. 
Hence, the tensile tester has to be designed such that precise measurement of macroscopic strain is possible.

The tensile machine has been designed to allow for loading along two normal axis cruciform substrates coated by the studied films. The mechanical loading tester is depicted schematically in Fig. 2. The set-up is shown in Fig. 3 within the DiffAbs experimental station at Soleil. The biaxial tester is shown mounted on the six axis goniometer.

The machine is compact $3.5 \mathrm{~kg}$ in weight, $19 \times 19 \times 8.5 \mathrm{~cm}^{3}$ in size with an empty centre and is designed to allow x-ray diffraction at glancing angles (no shadowing edges). Two couples of motors and force sensors are fixed to the device frame. The 4 motors can be actuated separately in order to keep the studied area at a fixed position in the goniometer (Fig. 2). This ensures that the same volume of material is being analyzed while as detailed in section III, it also ensures that this volume is included in a uniformly strained zone even in the case of non equibiaxial loading. All force sensors were first calibrated using dead weights $(6.894+$ $\mathrm{n} * 49.03 \mathrm{~N}$ with $\mathrm{n}=1$ to 4 ). In the range $0-200 \mathrm{~N}$, the load cell precision is $0.07 \mathrm{~N}$.

The cruciform substrates were coated at their centre only and gripped by a cam rotating in a cylindrical fixation. Here, we used $125 \mu \mathrm{m}$ thick polyimide called Sofimide from Micel company, France. This polymer allows handling the metallic film safely while reducing the contribution of the substrate to the mechanical response of the sample thanks to the low elastic modulus of the polyimide with respect to the metallic coating (see table I). ${ }^{26,27}$

Once the coated substrate is set and gripped in the machine, the test is carried out and displacement-controlled by incremental steps. The forces are measured for each arm. All electronic signals have been set to SOLEIL Synchrotron standards and are monitored during the whole experiments.

An optical setup is fixed underneath the testing machine (Fig. 3) to capture pictures of the back side surface of the specimens at each load step. The optical microscope is composed of a 
telecentric lens (x 0.5 or x 1.0 from Edmund Optics) and a CCD camera (Pixelfly QE-12bits dynamic range, horizontal x vertical : 1392 x 1024 pixels resolution and a pixel size $6.45 \times$ $6.45 \mu \mathrm{m}^{2}$, black and white). The size of the region of interest at the sample surface is $18 \times 12.6$ $\mathrm{mm}^{2}$ and $9 \times 6.3 \mathrm{~mm}^{2}$ for the $\mathrm{x} 0.5$ and $\mathrm{x} 1.0$ lenses respectively. Pixelfly QE CCD camera system was chosen because of its compact size since the telecentric lens plus camera are located below the deformation stage and because of its low readout noise (7e-rms) associated. This non-cooled camera was designed for industrial and scientific applications needing a high sensitivity. Pictures are recorded with the ImageJ (Image processing and analysis in Java) plug-ins in 16-bit tagged image file (.tif) format. ${ }^{28}$

Digital Image Correlation (DIC) is then used to measure in-plane displacement fields of the substrate and to evaluate the average in-plane strains. It consists in registering pictures shot at different stages of loading. In the present case, a global approach to DIC is utilized. It consists in measuring a displacement field discretized with a finite element mesh made of 4-noded elements with a bilinear displacement interpolation. ${ }^{29}$ In the future, it is planed to control the testing machine by resorting to DIC. ${ }^{30}$ It is worth noting that to avoid spurious effects induced by out-of-plane motions in monovision, a telecentric lens was used.

One important aspect of DIC is to evaluate the performance of the technique in terms of displacement and strain resolutions. In the present case, ten pictures were shot for each analyzed load level. In particular, prior to the experiment itself, ten pictures were shot in addition to the reference picture. The correlation analysis is run and the standard deviation associated with the measured displacement field is evaluated and will be referred to as displacement resolution. An average value of three pixels is found for an element of area equal to $16 \times 16$ pixels. The same procedure is then performed to evaluate the strain resolution, which is equal to $3 \times 10^{-3}$ when the average strain per element is computed. The resolution can be further reduced by interpolating the measured displacements with a bilinear 
polynomial prior to its spatial derivation to evaluate strains. In the following analyses, the achieved strain resolution is less than $3 \times 10^{-5}$. When comparing these two resolutions, it is concluded that in the present case for which strains are of the order of a few $10^{-3}$, the analysis of the strain field is not possible (resolution: $3 \times 10^{-3}$ ), however the evaluation of the mean strain (resolution: $3 \times 10^{-5}$ ) can be trusted. For the all measurements, the $\mathrm{x} 1.0$ telecentric lens was used.

\section{STRAIN AND STRESS FIELDS}

One of the most challenging aspects in biaxial testing set ups is the specimen design. ${ }^{31,32}$ To perform a biaxial test on sheet material, a cross-shaped specimen is typically used, i.e. cruciform specimen. The objective of the present study is to check that we can perform in situ x-ray strain measurements with high accuracy. Hence, the specimen design was governed by the following constraint: the centre of the substrate specimen must exhibit a homogeneous strain area larger than the irradiated area i.e. a few $\mathrm{mm}^{2}$. Contrary to some studies, ${ }^{32}$ it is not of great importance to have the majority of deformation at the centre of the specimen and to avoid stress concentrations in other regions of the specimen.

\section{A. Equibiaxial loading}

The geometry of the cruciform substrate has to be carefully designed and checked to shift the maximum stressed zone off the central zone where is to be generated a uniform strain field. Following Makinde et al. ${ }^{33}$ work, we used finite elements analysis (FEA) to calculate both stresses and strains under biaxial loading forces (Figs. 4 and 5). The most important region is obviously the central one where elastic strains are measured using x-ray diffraction. CASTEM code from CEA was employed to carry out the calculations. Fig. 4 shows both principal strains $\varepsilon_{\mathrm{xx}}$ and $\varepsilon_{\mathrm{yy}}$ for equibiaxial forces. Both figures are complementary under such 
conditions. We checked that under a $50 \mathrm{~N}$ equibiaxial loading, a $0.3 \%$ uniform strain was generated in a central area of $8 \mathrm{~mm}$ in diameter of the cruciform substrate with $20 \mathrm{~mm}$ in width arms and $5 \mathrm{~mm}$ toe weld while the used X-ray beam section at the goniometer center is $1 \times 0.3 \mathrm{~mm}^{2}$ (Fig. 4). This used geometry allows for concentrating the Von Mises stress maxima outside the tested central zone as shown on Fig. 5 where the stress profile emphasizes the constant and lower stress in the central zone. ${ }^{34}$

It is noteworthy that the calculated stress values about $20 \mathrm{MPa}$ are well below the yield strain value estimated for sofimide at about $50 \mathrm{MPa}$ in comparison to Kapton tabulated value. ${ }^{27}$ However, this calculation could be obtained with a two dimensional approach in the case of a bare substrate. The actual tested specimens are more complex since they are coated on their upper side. This requires a three dimensional approach. In the next section, the measurements are carried out for coated substrates in order to extract thin film elastic strains and to check the design of the optimized geometry of the cruciform.

\section{B. Non-equibiaxial loading}

Figure 6 shows both principal strains $\varepsilon_{\mathrm{xx}}$ and $\varepsilon_{\mathrm{yy}}$ for non equibiaxial forces. Obviously now, both figures are not complementary.

It is important to point out that the size of the uniformly strained area will dependent upon the direction $\mathrm{x}$ or $\mathrm{y}$. In the present case where $\mathrm{F}_{\mathrm{x}}<\mathrm{F}_{\mathrm{y}}$ extension of this zone is larger along $\mathrm{x}$ axis (Fig. 6). In sake of clarity, we calculated the extension at $45^{\circ}$ from $x$ and $y$ axis of the area uniformly strained within an error of less than $1 \%$. The values obtained for $\varepsilon_{\mathrm{xx}}$, and $\varepsilon_{\mathrm{yy}}$ are plotted in Fig. 7 as a function of $\mathrm{F}_{\mathrm{x}} / \mathrm{F}_{\mathrm{y}}$ ratio.

We note that these sizes diminish as the $F_{x} / F_{y}$ ratio decreases, that is when load dissymmetry increases. The minimum value is obtained for $\varepsilon_{\mathrm{xx}}$ strain at about $0.2 \mathrm{~mm}$ in the explored and used range of $F_{x} / F_{y}$ ratios. Noticeably this value of $0.2 \mathrm{~mm}$ is of the order of one size of the 
used x-ray beam section at sample surface that is 1 arger than $1 \times 0.3 \mathrm{~mm}^{2}$. Therefore, care is to be taken to position the beam at the very central position of the cruciform. It is worth noting that such minimum is obtained only for $\varepsilon_{\mathrm{xx}}$ strain while monotonous decrease is observed for both $\varepsilon_{\mathrm{yy}}$ and $\varepsilon_{\mathrm{xy}}$ strains. These results from a change in the sign of the $\varepsilon_{\mathrm{xx}}$ strain that changes from tensile at the centre to compressive in the area surrounding the central and studied zone (Fig. 6).

\section{TUNGSTEN COATED POLYIMIDE SUBSTRATE TESTING}

\section{A. Characteristics of the films}

For the preliminary tests, we studied $\mathrm{W}$ that is elastically isotropic. So far, the measured Poisson ratio of $\mathrm{W}$ thin films produced by physical vapor deposition (PVD) techniques is 0.26 ${ }^{35}$ ( 0.284 for the bulk) while we measured 0.37 for the polyimide substrate. ${ }^{26}$ These values correspond to a relative Poisson ratio mismatch of $30 \%$. In the following the tests were carried out to impose an equibiaxial stress field to the coated substrate.

The $\mathrm{W}$ thin films were produced at room temperature by PVD technique with an Ar+-ion-gun sputtering beam at $1.2 \mathrm{keV}$ (Kaufman ion source) in a NORDIKO-3000 system. The base pressure of the deposition chamber was $7 \times 10^{-5} \mathrm{~Pa}$ while the working pressure during films growth was approximately $10^{-2} \mathrm{~Pa}$ (For more details see Faurie et al.). ${ }^{15}$ Under these conditions, high compressive residual stresses $(\sim-2 \mathrm{GPa})$ are obtained and are beneficial for the tensile tests since cracking is prevented. Moreover a $\{110\}$ texture is detected with a degree of scatter given by the full width at half maximum (FWHM) of the peaks of the $\Psi$ scan of $10^{\circ}$.

B. X-ray strain analysis 
The x-ray elastic constants (XEC) $\mathrm{S}_{1}^{\mathrm{hkl}}$ and $\frac{1}{2} \mathrm{~S}_{2}^{\mathrm{hkl}}$ of polycrystalline materials link the experimental observed in-grain strains (by means of diffraction methods) to the macroscopic stresses. They depend on the lattice plane under study and generally differ from the mechanical elastic constants according to the anisotropy of the crystals and due to the fact that only a specific part of all crystals contribute to the diffraction experiments, i.e. those crystallites with the specific lattice plane oriented perpendicular to the direction of measurement.

In the specific case of a perfect isotropic material such as $\mathrm{W}$, the length-scale change is straightforward since the film is locally elastically homogeneous. Assuming a planar stress state (i.e. neglecting shear stress), x-ray measured strains reduce to: ${ }^{8,9}$

$\{\varepsilon\}_{\Phi \Psi}^{\mathrm{hkl}}=\frac{1}{2} \mathrm{~S}_{2}^{\mathrm{hkl}} \cdot\left(\sigma_{\mathrm{xx}} \cos ^{2} \Phi+\sigma_{\mathrm{yy}} \sin ^{2} \Phi\right) \cdot \sin ^{2} \Psi-\mathrm{S}_{1}^{\mathrm{hkl}} \cdot\left(\sigma_{\mathrm{xx}}+\sigma_{\mathrm{yy}}\right)$

With $S_{1}^{\text {hkl }}=-\frac{v_{\mathrm{f}}}{E_{\mathrm{f}}}$ and $\frac{1}{2} S_{2}^{\text {hkl }}=\frac{1+v_{\mathrm{f}}}{E_{\mathrm{f}}}$ for a locally isotropic material such as W.

where $E_{\mathrm{f}}$ and $v_{\mathrm{f}}$ are the film Young's modulus and Poisson's ratio respectively, $\sigma_{\mathrm{xx}}$ and $\sigma_{\mathrm{yy}}$ the in-plane principal stress components. $\Phi$ is the rotation angle around film surface normal and $\Psi$ the angle between the normal of the diffracting planes and the normal of the specimen surface (Fig. 3).

This equation can be written in terms of principal strains $\varepsilon_{\mathrm{xx}}, \varepsilon_{\mathrm{yy}}$ and $\varepsilon_{\mathrm{zz}}$ :

$$
\{\varepsilon\}_{\Phi \Psi}^{\mathrm{hkl}}=\left[\left(\varepsilon_{\mathrm{xx}}-\varepsilon_{\mathrm{zz}}\right) \cos ^{2} \Phi+\left(\varepsilon_{\mathrm{yy}}-\varepsilon_{\mathrm{zz}}\right) \sin ^{2} \Phi\right] \cdot \sin ^{2} \Psi+\varepsilon_{\mathrm{zz}}
$$

We used two particular angles $\Phi=0^{\circ}$ and $90^{\circ}$ for the experiments. Strains write in these two cases:

$\{\varepsilon\}_{0 \Psi}^{\mathrm{hkl}}=\left(\varepsilon_{\mathrm{xx}}-\varepsilon_{\mathrm{zz}}\right) \sin ^{2} \Psi+\varepsilon_{\mathrm{zz}}$

and 
$\{\varepsilon\}_{90 \Psi}^{\mathrm{hkl}}=\left(\varepsilon_{\mathrm{yy}}-\varepsilon_{\mathrm{zz}}\right) \sin ^{2} \Psi+\varepsilon_{\mathrm{zz}}$

For an equibiaxial stress field $\left(\sigma_{x x}=\sigma_{y y}=\sigma\right)$, strain is independent of $\Phi$ and Eq. (1) writes

$\{\varepsilon\}_{\Phi \Psi}^{\mathrm{hkl}}=\frac{1}{2} \mathrm{~S}_{2}^{\mathrm{hkl}} \cdot \sigma \cdot \sin ^{2} \Psi-\mathrm{S}_{1}^{\mathrm{hkl}} \cdot 2 \sigma$

And in terms of principal strains (with $\varepsilon_{\mathrm{xx}}=\varepsilon_{\mathrm{yy}}$ ), Eq. (2) writes:

$\{\varepsilon\}_{\Phi \Psi}^{\mathrm{hkl}}=\left(\varepsilon_{\mathrm{xx}}-\varepsilon_{\mathrm{zz}}\right) \cdot \sin ^{2} \Psi+\varepsilon_{33}=\left(\varepsilon_{\mathrm{yy}}-\varepsilon_{\mathrm{zz}}\right) \cdot \sin ^{2} \Psi+\varepsilon_{33}$

The linear relationship between strain and $\sin ^{2} \Psi$ (so called $\sin ^{2} \Psi$ method) is hence established for a single phase elastically isotropic material. So far, most materials show anisotropic elasticity and a grain interaction model has to be chosen to relate x-ray strains to macroscopic strains. The mechanical behavior of a polycrystalline thin film is then determined by the distribution of the crystallite orientations within the thin film and the grain interaction. $^{17,36}$

\section{Experimental responses}

Figure 8 shows the $\mathrm{x}$-ray strains for the (211) reflection extracted along both directions ( $\Phi=0^{\circ}$ and $\Phi=90^{\circ}$ ) for 6 loading states (T1 to T6) measuring the Bragg peak shifts for different inclination of the specimen (different angle $\Psi$ between the sample normal and the diffraction plane normal). The strain is calculated using the unloaded state $\mathrm{T} 0$ as a reference

state: $\{\varepsilon\}_{\Phi \Psi}^{211}=\ln \left(\sin \theta_{\Phi \Psi}^{\mathrm{T} 0} / \sin \theta_{\Phi \Psi}^{\mathrm{TX}}\right)$ where $\theta_{\Phi \Psi}^{\mathrm{T} 0}$ is the angular position of the considered diffraction peak for the unloaded state and $\theta_{\Phi \Psi}^{\mathrm{TX}}$ the corresponding angle for the loaded state TX. As commonly adopted strain is plotted as a function of $\sin ^{2} \Psi$. All curves are linear as expected for a locally isotropic material. ${ }^{15}$ As the load increases, the slope of the related curves increases gradually with a loading sequence increasing from T1 to T6. As can be 
noticed from Eq. (1), the $\varepsilon$-vs- $\sin ^{2} \psi$ straight lines should cross in one point. The accomplishment of this criterion is significant of experimental accuracy.

The obtained experimental values fall in the $\sin ^{2} \Psi$ range of $0.41-0.44$ which corresponds to $v$ of range $0.26-0.284$, these values being calculated with $\sin ^{2} \Psi=2 v / 1+v$ obtained from Eqs. 1-6 with a strain equal to zero.

For each loading state, combining the slope and the extrapolations at $\sin ^{2} \Psi=1$ of linear fits, using Eqs. (3) and (4), allow to determine principal strains $\varepsilon_{\mathrm{xx}}, \varepsilon_{\mathrm{yy}}$ and $\varepsilon_{\mathrm{zz}}$ (Fig. 9). $\varepsilon_{\mathrm{xx}}, \varepsilon_{\mathrm{yy}}$ are determined both in tension while $\varepsilon_{z z}$ is in compression. The ratio of the out-of-plane to the in-plane strain is found to be about -0.71 close to the expected value of $\frac{2 v}{v-1}(-0.7$ for $v$ of 0.26). For all loading states, in-plane principal strains along both directions $\left(\Phi=0^{\circ}\right.$ and $\Phi=90^{\circ}$ ) are determined in a difference of less than $15 \%$ within the elastic deformation range of the film.

In Fig. 10, x-ray strain $\varepsilon_{\mathrm{xx}}$ values are compared to the DIC and FEM ones over the complete loading ramp with a relatively good agreement being obtained.

A loading path comprising both non-equibiaxial and equibiaxial loadings was carried out to test the potentiality of the machine and explore the loading map (Fig. 1). Controlled nonequibiaxial measurements have been made uniaxially and in the critical regime with a force ratio $\sim 0.5$ where the homogeneously deformed zone is expected to be of minimum size (Fig. 7). The measured strains are reported in Fig. 11 for all loading steps. Again, a relatively good agreement between x-ray and FEM strains is obtained for equi-biaxial loadings. In contrast, discrepencies are observed for non equi-biaxial loadings and are to be attributed to the irradiation of a zone larger than the homogeneously strained one. Under such loading 
conditions, smaller $\mathrm{x}$-ray beam sizes will be used in the future, the ultimate size of $10 \times 10 \mu \mathrm{m}^{2}$ being expected at DIFFABS-SOLEIL thanks to focusing optics.

\section{CONCLUSION AND PERSPECTIVES}

We have developed at the DIFFABS-SOLEIL beamline a biaxial tensile machine working in synchrotron environment for in-situ characterization of thin film mechanical response. Tests on model $\mathrm{W}$ films deposited on polyimide cruciform substrates show that, the device allows for setting a uniform strain field in the characterized volume of a film having a Poisson ratio mismatch with respect to the supporting substrate. To validate the experimental setup, an equibiaxial test has been performed in situ. The applied strains have been estimated from finite element analysis, and experimentally measured in situ both by x-ray diffraction and DIC. The three values agree quite well. Measurements made for non-equibiaxial tests show that smaller beam sizes are required since as expected from FEM the homogeneously deformed zone size decreases dramatically as the force ratio approaches 0.5. Further developments are aimed at developing dynamic testing controlled by a ramp of optical strain (determined at substrate backside surface). The objective is to integrate the biaxial loading as a routine tool for a XRD beamline (DIFFABS) and to extend applications to delamination and cracking of coatings as well as to more complex loading conditions involving shear, similar to what is encountered in real situation or engineering environments. The substrate behavior is also of utmost importance and a recent publication ${ }^{37}$ has proved the feasibility of measuring strains by XRD in both polyimide and metallic films thanks to the use of two dimensional detectors. Furthermore, taking advantage of focusing optics available at synchrotron sources, a strain/stress mapping of the strain field generated at the center of the sample would be useful to validate finite element calculations and optical measurements done at sample surface. In particular, the in-plane strain homogeneity zone could be determined with great accuracy. This kind of mapping is frequently/routinely encountered for covalent materials 
such as semi conductors and oxide films thanks to micro Raman ${ }^{38}$ but $\mu$ XRD feasibility has also been achieved in the case of metallic films. ${ }^{39}$

\section{Acknowledgements}

This work has been developed in the frame of the French Research Agency, project entitled Cmonano (ANR-05-NANO-069-03). 


\section{References}

${ }^{1}$ M.A. Meyers, A. Mishra, and D.J. Benson, Prog. Mater. Sci. 51, 427 (2006).

${ }^{2}$ J. Schiotz, T. Veege, F.D. Di Tolla, and K.W. Jacobsen, Phys. Rev. B 60, 11971 (1999).

${ }^{3}$ S. Yip, Nature 391, 532 (1998).

${ }^{4}$ H. Van Swygenhoven and J.R. Weertman, Mater. Today 9, 24 (2006).

${ }^{5}$ S. Cuenot, C. Frétigny, S. Demoustier-Champagne, and B. Nysten, Phys. Rev. B 69, 165410 (2004).

${ }^{6}$ F. Spaepen and D.Y.W. Yu, Scr. Mater. 50, 729 (2004).

${ }^{7}$ E. Artz, Acta Mater. 46, 5611 (1998).

${ }^{8}$ V. Hauk (1997), Structural and residual stress analysis by non destructive methods: Evaluation, application, assessment. Amsterdam, Elsevier Science.

${ }^{9}$ I.C. Noyan, J.B. Cohen (1987) Residual stresses. Measurements by diffraction and interpretation, New York: Springer Verlag.

${ }^{10}$ E.L. Bartholomew and R.R. Beiderman, Rev. Sci. Instrum. 37, 77 (1966).

${ }^{11}$ J. Kobayashi, N. Yamada, and T. Azumi, Rev. Sci. Instrum. 39, 1647 (1968).

${ }^{12}$ A. M. Korsunsky, K. E Wells, and P. J. Withers, Scr. Mater. 39, 1705 (1998).

${ }^{13}$ A. Wanner and D. C. Dunand, Metall. Mater. Trans. A 31, 2949 (2000).

${ }^{14}$ M. P. Miller, J.V. Bernier, J. S. Park, and A. Karimirov, Rev. Sci. Instrum. 76, 113903 (2005).

${ }^{15}$ D. Faurie, P.-O. Renault, E. Le Bourhis, P. Villain, Ph. Goudeau, and K. F. Badawi, Thin Solid Films 469-470, 201 (2004).

${ }^{16}$ J. Böhm, P. Gruber, R. Spolenak, A. Stierle, A. Wanner, and E. Arzt, Rev. Sci. Inst. 75, 1110 (2004).

${ }^{17}$ D. Faurie, O. Castelnau, R. Brenner, P.-O. Renault, E. Le Bourhis, Ph. Goudeau, J. Appl. Cryst. 42, 1073 (2009). 
${ }^{18}$ N.A. Mara, D. Bhattacharyya, R.G. Hoagland, and A. Misra, Scr. Mater. 58, 874 (2008).

${ }^{19}$ D. Lacour, J. A. Katine, L. Folks, T. Block, J. R. Childress, M. J. Carey, and B. A. Gurney, Appl. Phys. Lett. 84, 1910 (2004).

${ }^{20}$ C. Jones and R. Greene, Mater. World 9, 19 (2001).

${ }^{21}$ J. J. Vlassak and W. D. Nix, J. Mater. Res. 7, 3242 (1992),

${ }^{22}$ A. J. Kalkman, A. H. Verbruggen, G. C. A. M. Janssen, Rev. Sci. Instr. 74, 1383 (2003).

${ }^{23}$ S. Eve, N. Hubert, O. Kraft, A. Last, D. Rabus, M. Schlagenhof, Rev. Sci. Instr. 77, 103902 (2006).

${ }^{24}$ J. Keckes, E. Eiper, K.J. Martinschitz, H. Ko stenbauer, R. Daniel, C. Mitterer, Rev. Sci. Instrum. 78, 036103 (2007).

${ }^{25}$ T.K. Schmidt, T.J. Balk, G. Dehm, E. Arzt, Script. Mater. 50, 733 (2004).

${ }^{26}$ S. Djaziri, Master of Science Thesis, Poitiers University (2009).

${ }^{27}$ DuPont, Materials data sheet No H-38492-2 for Kapton ${ }^{\circledR}$. DuPont de Nemours GmbH, Bad Homburg, Germany.

${ }^{28}$ Image $\mathrm{J}$ is a public domain Java image processing program inspired by NIH Image for the Macintosh (http://rsbweb.nih.gov/ij/). It was designed with an open architecture that provides extensibility via Java plug-ins (http://www.pco.de/drivers/). Custom acquisition, analysis and processing plug-ins can be developed using ImageJ's built in editor and Java compiler.

${ }^{29}$ G. Besnard, F. Hild, S. Roux, Exp. Mech. 46, 789 (2006).

${ }^{30}$ X. Fayolle, S. Calloch, F. Hild, Exp. Tech. 31, 57 (2007).

${ }^{31}$ A. Hannon and P. Tiernan, J. Mater. Proc. Techn. 198, 1 (2008).

${ }^{32}$ S. Demmerle and J.P. Boehler, J. Mech. Phys. Solids 41, 143 (1993).

${ }^{33}$ A. Makinde, L. Thibodeau, and K. W. Neale, Experimental Mechanics 32, 138 (1992).

${ }^{34}$ M. Geiger, W. Hussnätter, and M. Merklein, J. Mater. Process. Technol. 167, 177 (2005). 
${ }^{35}$ P. O. Renault, K. F. Badawi, L. Bimbault, P. Goudeau, E. Elkaïm and J. P. Lauriat, Appl. Phys. Lett. 73, 1953 (1998).

${ }^{36}$ S. Matthies, H. G. Priesmeyer, M. R. Daymond, J. Appl. Cryst. 34, 585 (2001).

${ }^{37}$ G. Geandier, P.-O. Renault, E. Le Bourhis, Ph. Goudeau, D. Faurie, C. Le Bourlot, Ph. Djemia, O. Castelnau, S.M. Cherif, Appl. Phys. Lett. 96, 041905 (2010).

${ }^{38}$ T. Beeche, S. Graham, S. P. Kearney, L. M. Phinney, J. R. Serrano, Rev. Sci. Instrum. 78, 061301 (2007).

${ }^{39}$ P. Goudeau., P. Villain, N. Tamura, H. A. Padmore, Applied Physics Letters 83, 51 (2003). 


\section{FIGURE CAPTIONS}

FIG. 1. (Colour on line) Exploration of the loading map of a thin film. The loading paths employed for the study are schematized (in blue : equibiaxial, in red : non equibiaxial).

FIG. 2. (Colour on line) Schematic representation of the biaxial machine, showing the cruciform substrate, gripped on 4 cylinders connected to force sensors and rotated by step motors. The frame and angles are introduced in section IV.B. [x, y, z] is the specimen reference frame. $\Psi$ is the declination angle between the scattering vector $\mathbf{q}$ direction and the surface normal ones. $\Phi$ is the azimuthal angle defined in the film plane.

FIG. 3. (Colour on line) Biaxial tensile device set on DIFFABS-SOLEIL goniometer. The optical microscope is located underneath the machine. $\mathrm{X}$ ray beam and detector directions are shown. A focus shows the cruciform installed on the device with its central part being coated.

FIG. 4. (Colour on line) FEM of the strain field in a cruciform substrate loaded under equibiaxial forces of $100 \mathrm{~N}$ a) $\varepsilon_{\mathrm{xx}}$ b) $\varepsilon_{\mathrm{yy}}$. Insets show the respective strain profile along the line shown on the cruciform.

FIG. 5. (Colour on line) FEM of the Von Mises stress field in a cruciform substrate loaded under equibiaxial forces of 100 . Insets show the respective stress profile along the two lines shown on the cruciform. 
FIG. 6. (Colour on line) FEM of the strain field in a cruciform substrate loaded under nonequibiaxial forces of $F_{x}=50 N$ and $F_{y}=100 \mathrm{~N}$ a) $\varepsilon_{x x}$ b) $\varepsilon_{y y}$. These loading condition correspond to T6 loading state (see section 4).

FIG. 7. (Colour on line) Size of the uniformly (1\% deviation from central value) strained area as a function of $\mathrm{F}_{\mathrm{x}} / \mathrm{F}_{\mathrm{y}}$ ratio. The size is determined at $45^{\circ}$ from $\mathrm{x}$ and $\mathrm{y}$ axis.

FIG. 8. (Colour on line) $\mathrm{W}$ thin film $x$-ray strain as a function of $\sin ^{2} \psi$ for the (211) reflection: a) $\Phi=0^{\circ}$ and b) $\Phi=90^{\circ}$.

FIG. 9. (Colour on line) $\mathrm{W}$ thin film x-ray strains $\left(\varepsilon_{\mathrm{xx}}, \varepsilon_{\mathrm{yy}}\right.$ and $\left.\varepsilon_{\mathrm{zz}}\right)$ as a function of the applied load for an equi-biaxial loading. $\varepsilon_{\mathrm{zz}}$ was determined at similar amplitude for $\Phi=0^{\circ}$ and $\Phi=90^{\circ}$

FIG. 10. (Colour on line) x-ray, optical and finite elements strains as a function of the applied load for an equi-biaxial loading.

FIG. 11. (Colour on line) x-ray and finite elements strains as a function of the applied load ( $\varepsilon_{\mathrm{xx}}$ and $\left.\varepsilon_{\mathrm{yy}}\right)$ for a non equi-biaxial loading. 


\begin{tabular}{|c|c|c|c|}
\hline Material & $\begin{array}{l}\text { Young's modulus } \\
\text { (GPa) }\end{array}$ & Poisson's ratio & $\begin{array}{l}\text { Ultimate Tensile } \\
\text { strength }(\mathrm{MPa}) \text {. }\end{array}$ \\
\hline Tungsten & 411 & 0.28 & 1510 \\
\hline Sofimide CH / Kapton & $\mathrm{X} / 2.5^{*}$ & $\mathrm{X} / 0.34^{*}$ & \multirow{2}{*}{$165 / 231^{*}$} \\
\hline $\mathrm{HN}$ & $3.0 \pm 0.1 / 5.17 \pm 0.03 * *$ & $0.34 \pm 0.01 / 0.312 \pm 0.010 * *$ & \\
\hline
\end{tabular}

TABLE I. Mechanical characteristics of the two materials studied here. The values for polyimide substrates are given by the manufacturers*, Micel $\subset$ for sofimide $\mathrm{CH}$ and Dupont $\subset$ for Kapton $\mathrm{HN}$ for comparison and have also been measured** thanks to our optical device in the low applied strain range used for elastic properties study of deposited thin films. ${ }^{17}$ These two materials have similar characteristics: excellent property of heat resistance and wide range of working temperature. However, it is difficult to find reliable data in the literature for sofimide $\mathrm{CH}$ polymer. 


\begin{tabular}{|c|c|}
\hline Loading & $\begin{array}{c}\text { Applied load } \\
\text { step }\end{array}$ \\
\hline T1 & 5 \\
\hline T2 & 10 \\
\hline T3 & 15 \\
T4 & 25 \\
\hline T5 & 35 \\
\hline T6 & 44 \\
\hline
\end{tabular}

TABLE II. Applied loads used during the equi-biaxial tests. 


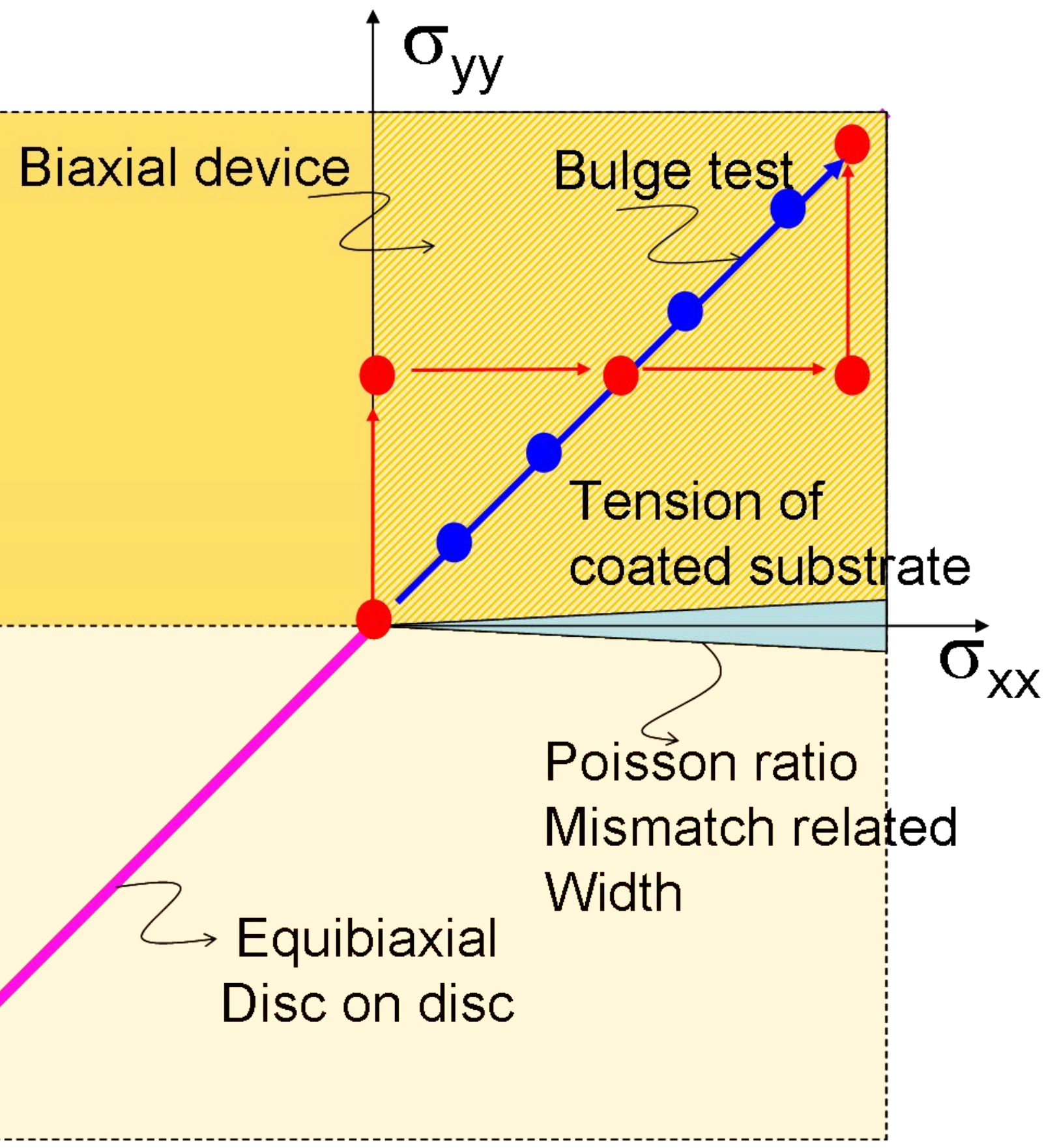




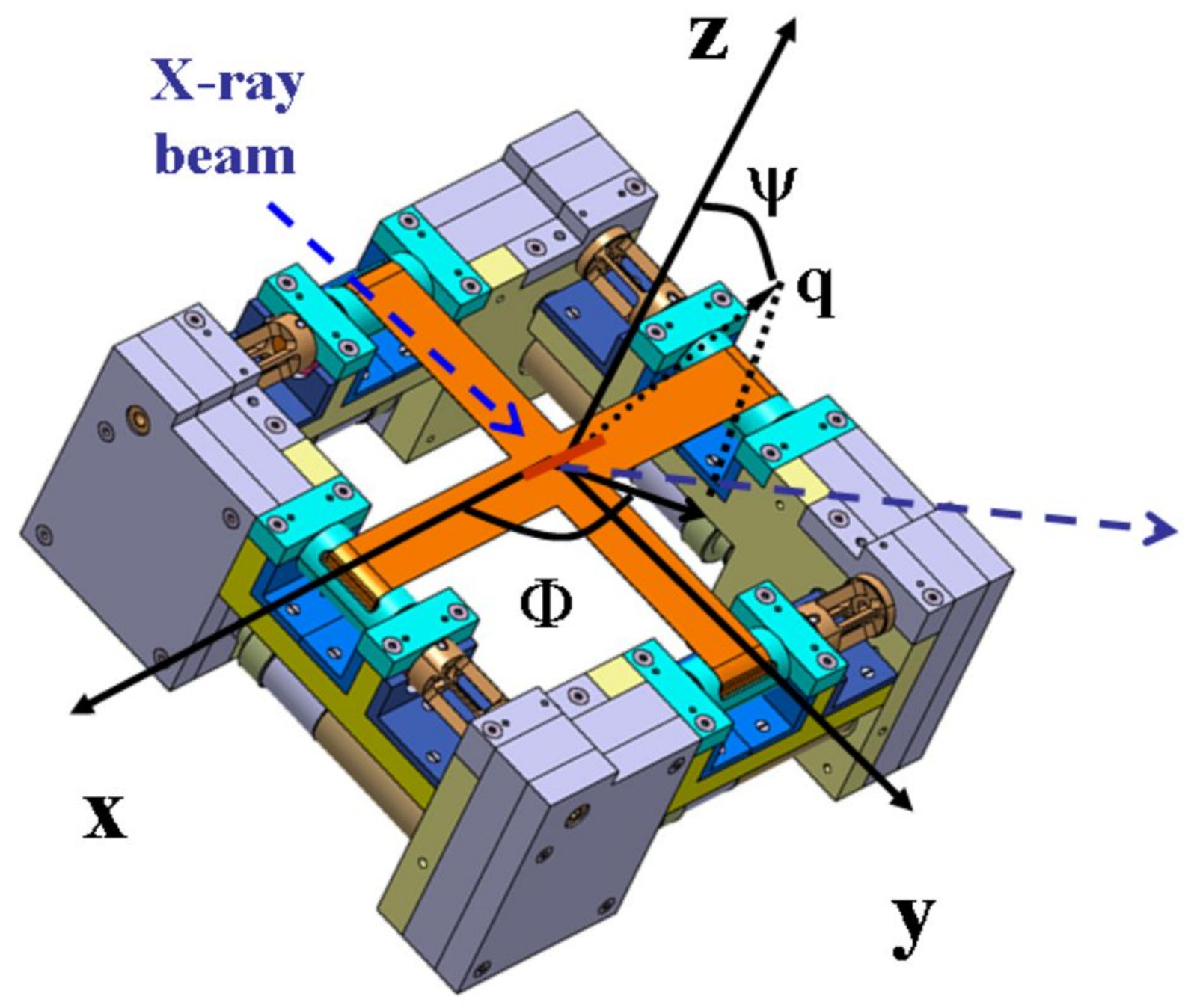




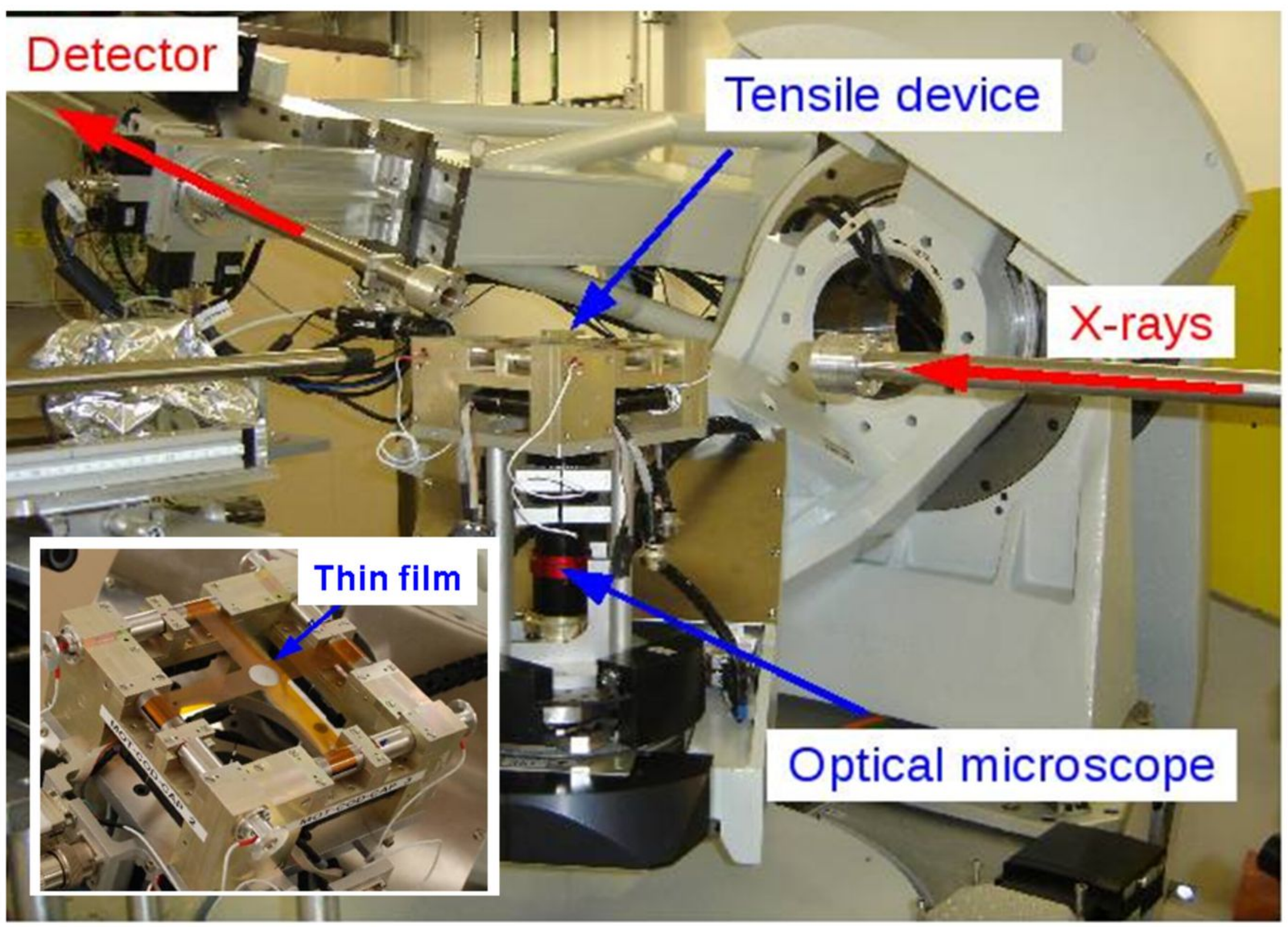




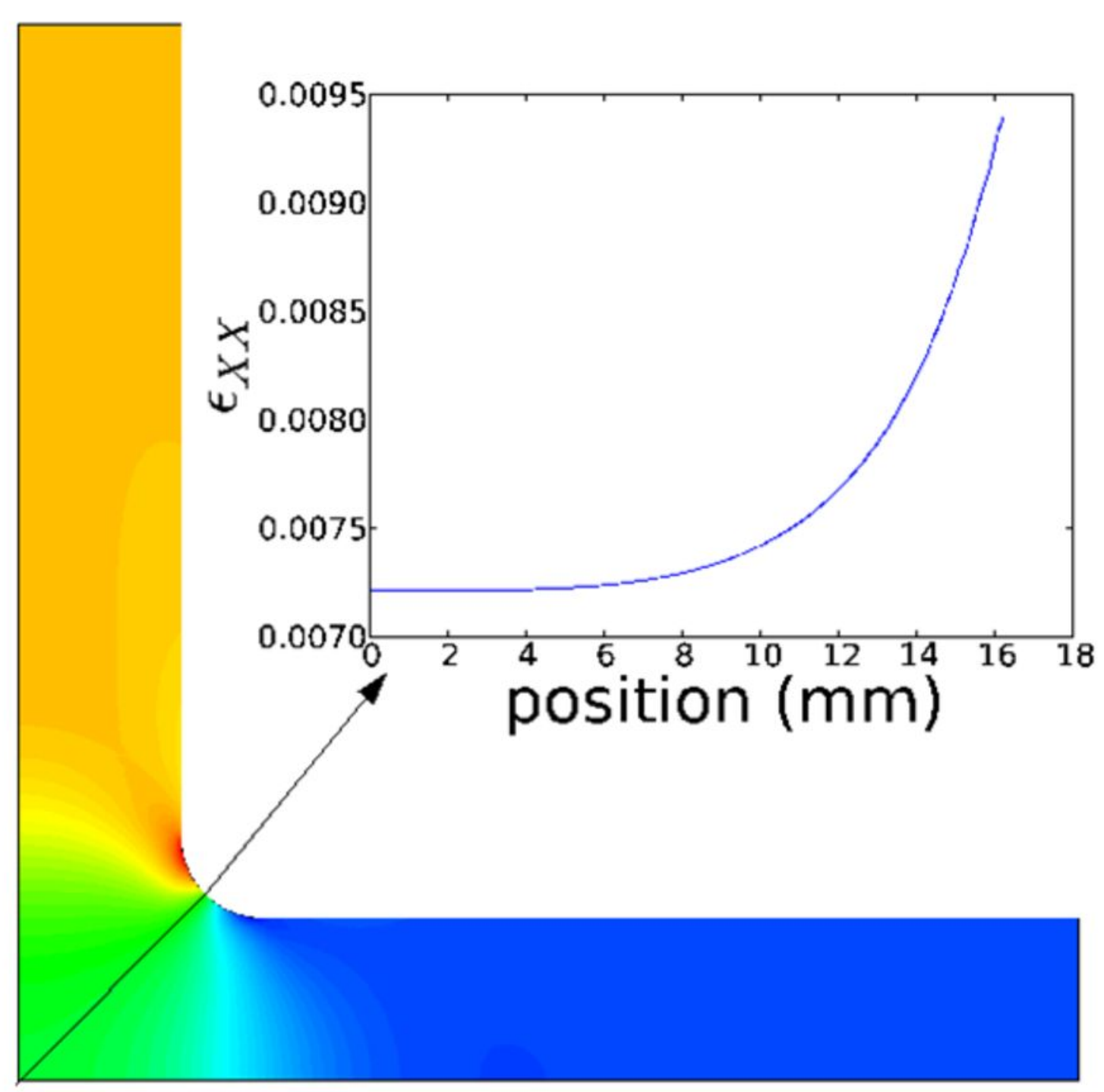
$\varepsilon_{\text {xx }}$
0.257
0.224
0.191
0.159
0.125
0.093
0.060
0.011
$-0.002$
$-0.005$
$-0.008$ 


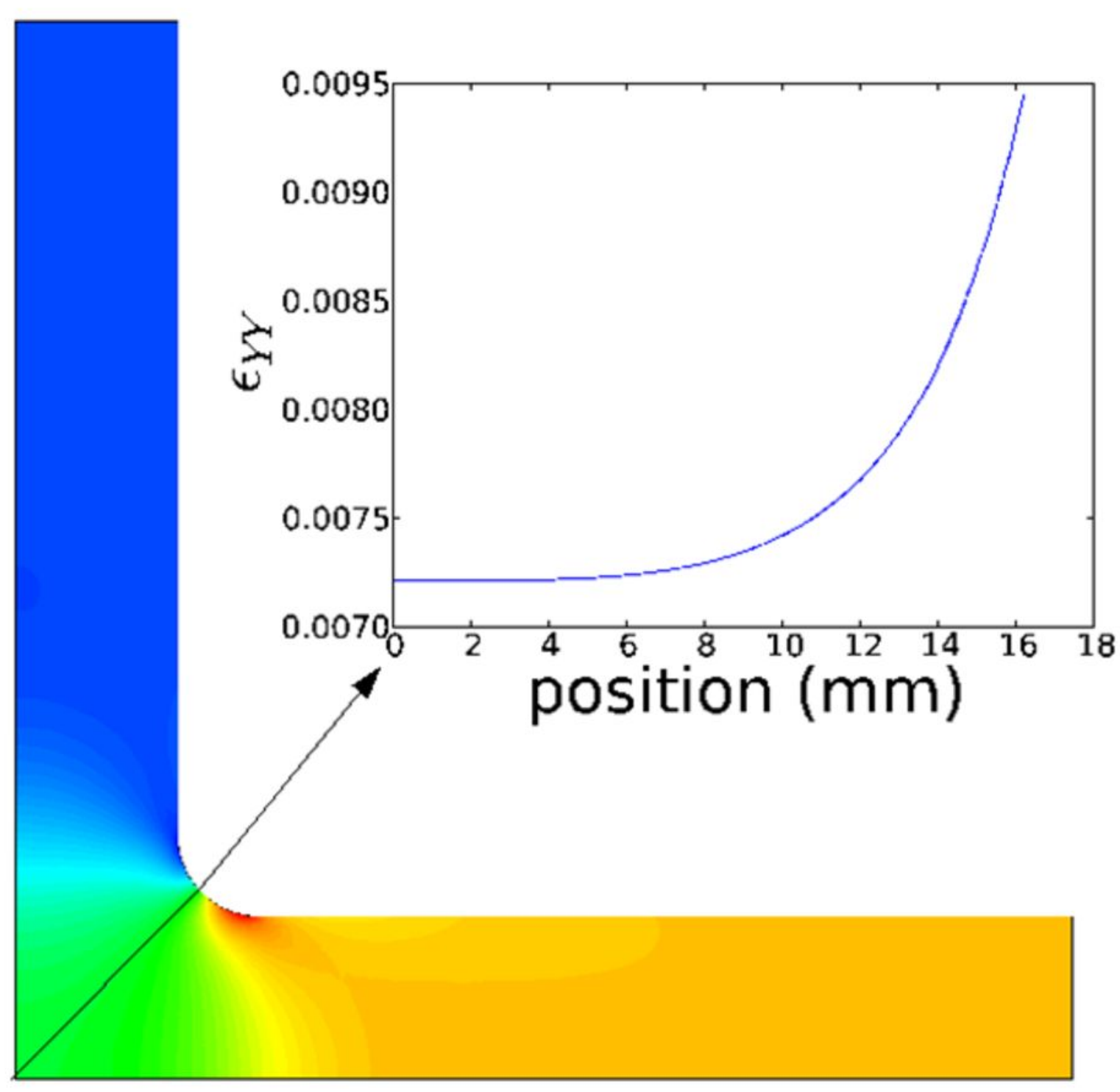

$\varepsilon_{\mathrm{YY}}$

0.257
0.224
0.191
0.159
0.125
0.093
0.060
0.011
-0.002
-0.005
-0.008




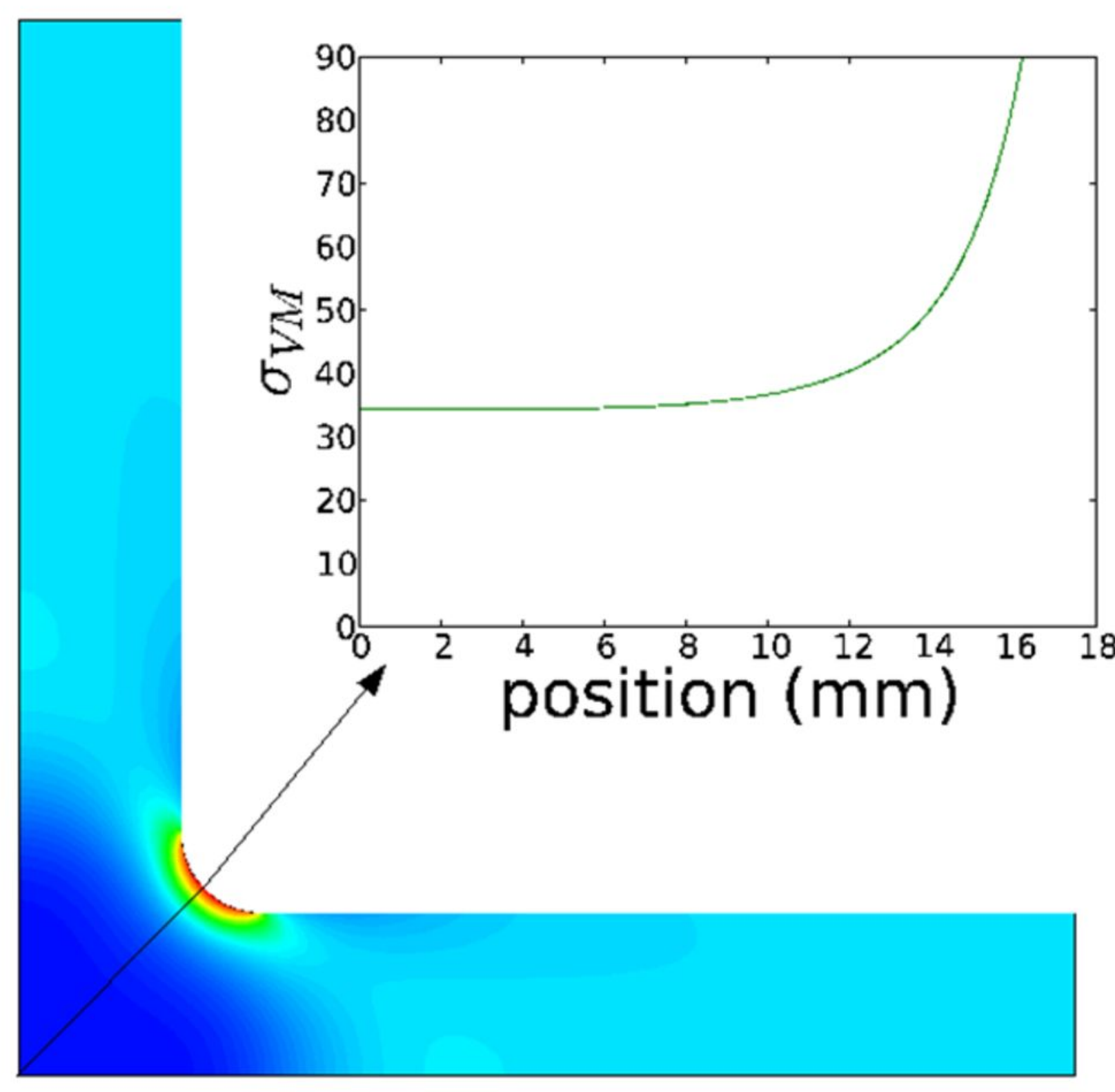

$\sigma_{\mathrm{m}}(\mathrm{MPa})$
90
79
74
69
63
58
53
48
43
37




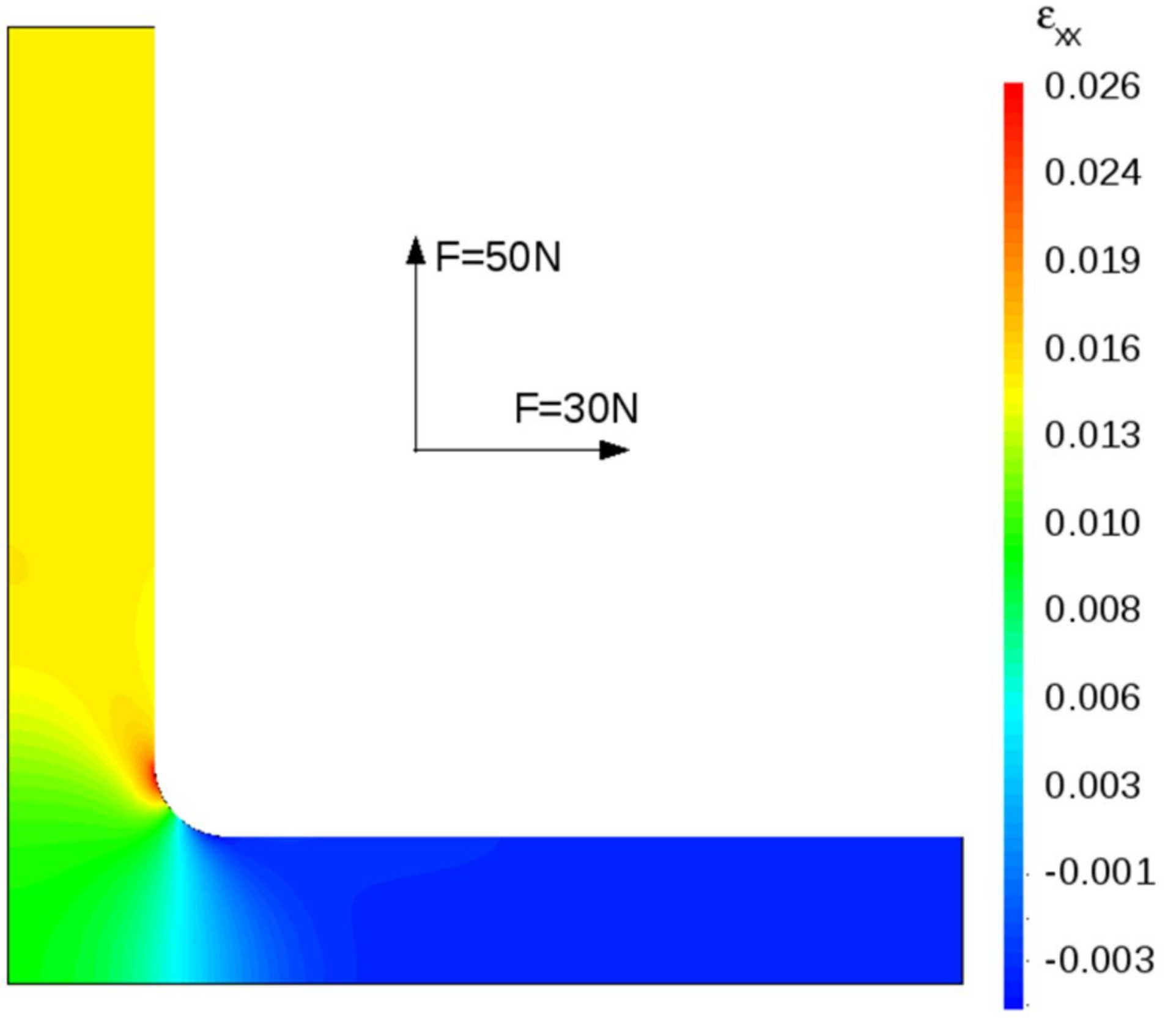




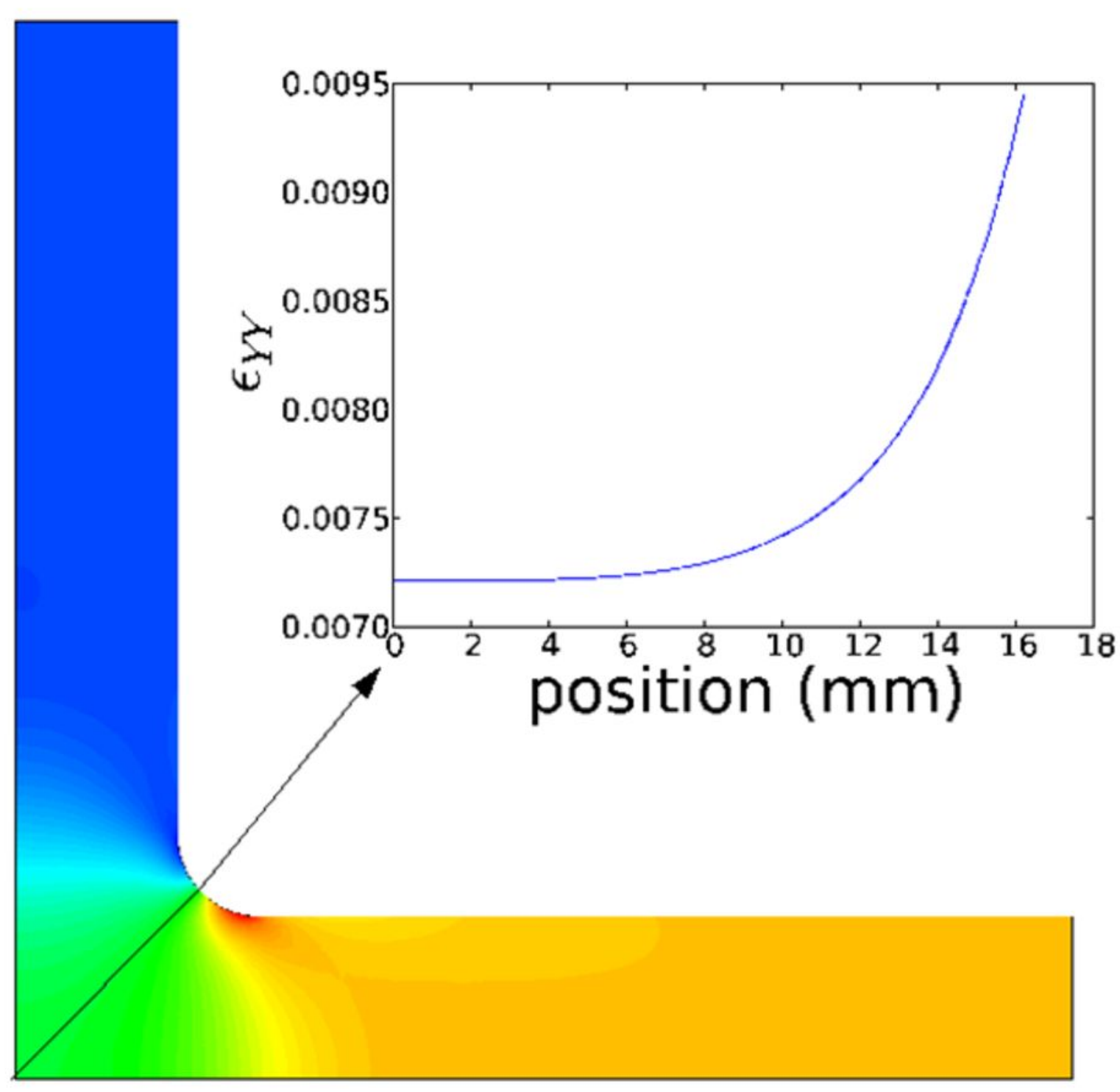

$\varepsilon_{\mathrm{YY}}$

0.257
0.224
0.191
0.159
0.125
0.093
0.060
0.011
-0.002
-0.005
-0.008




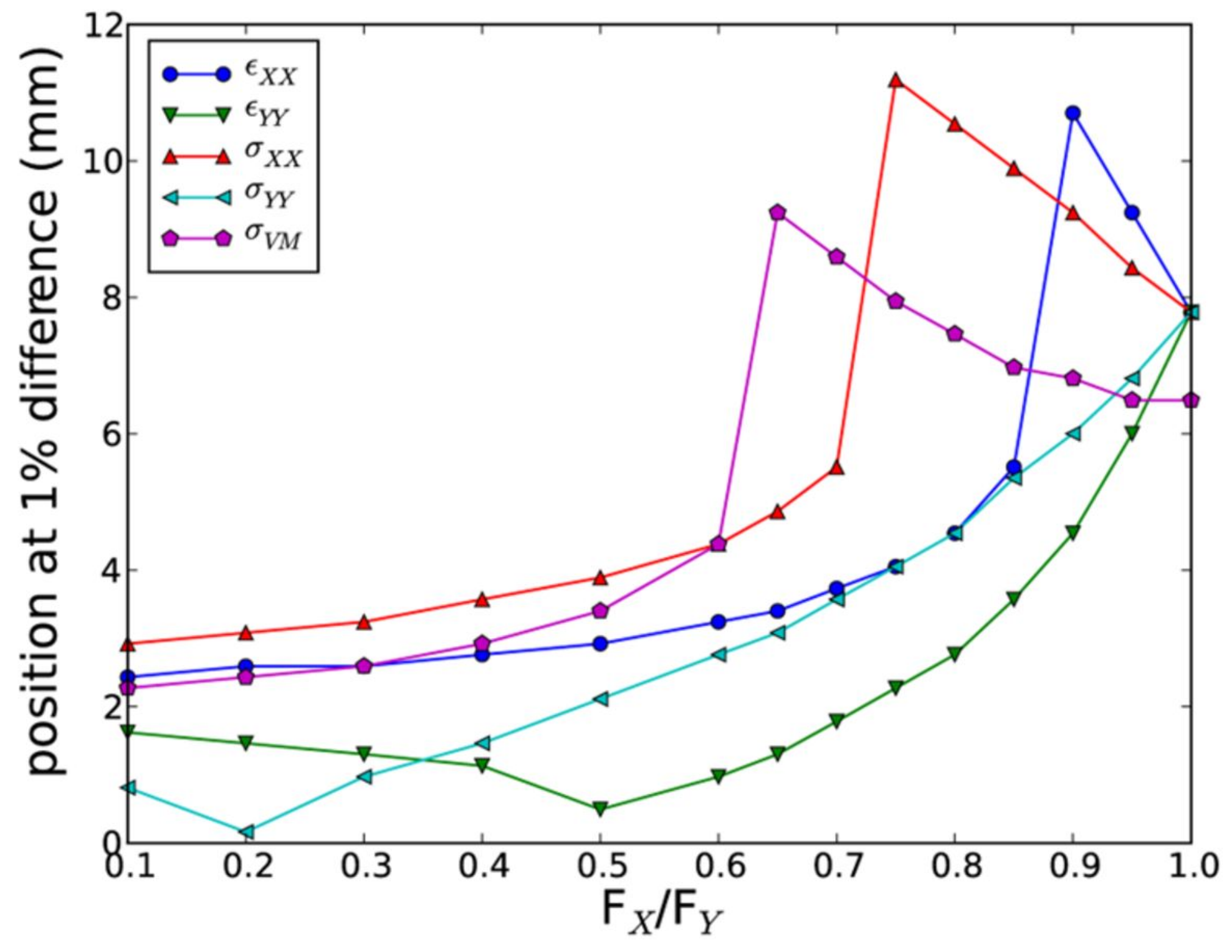




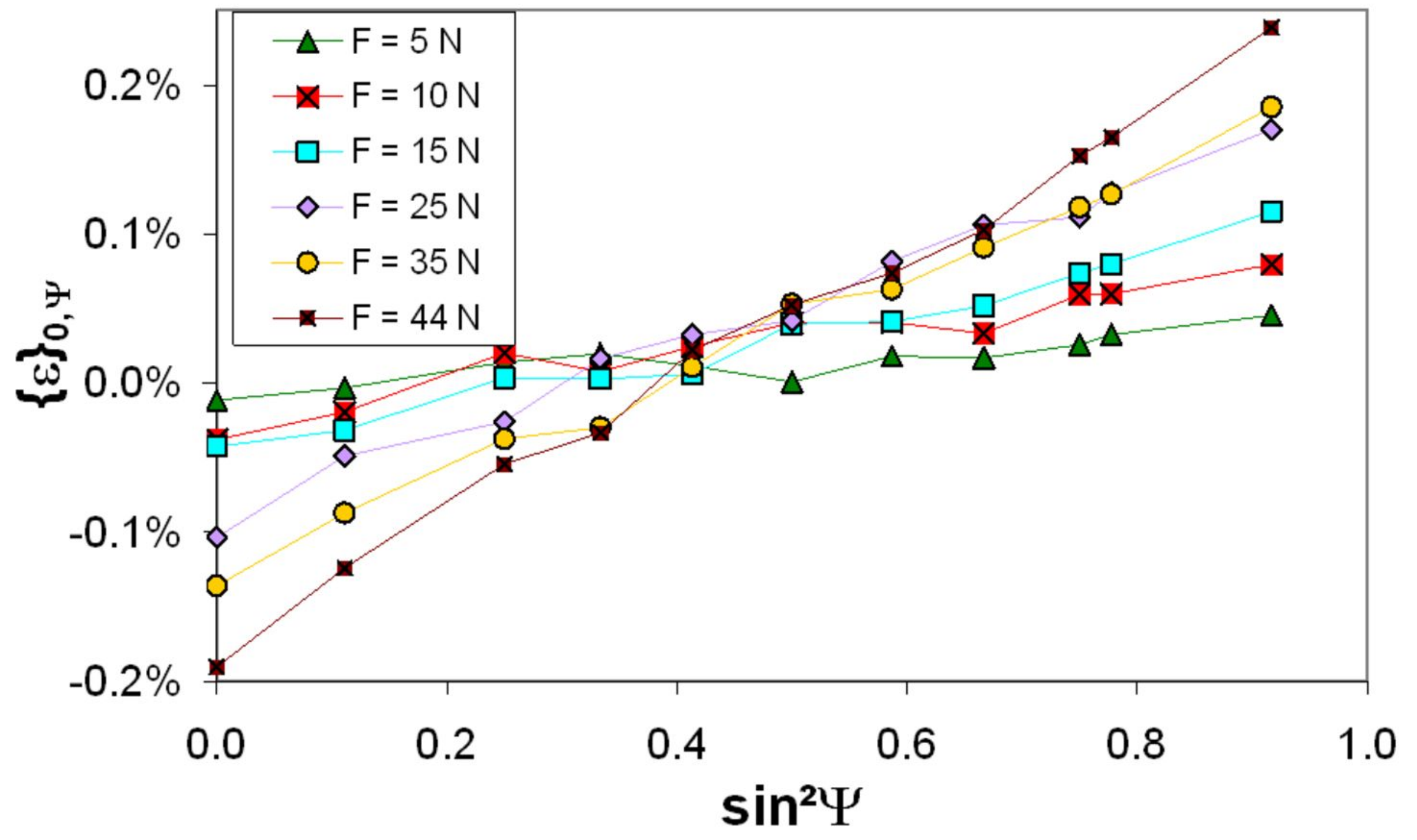




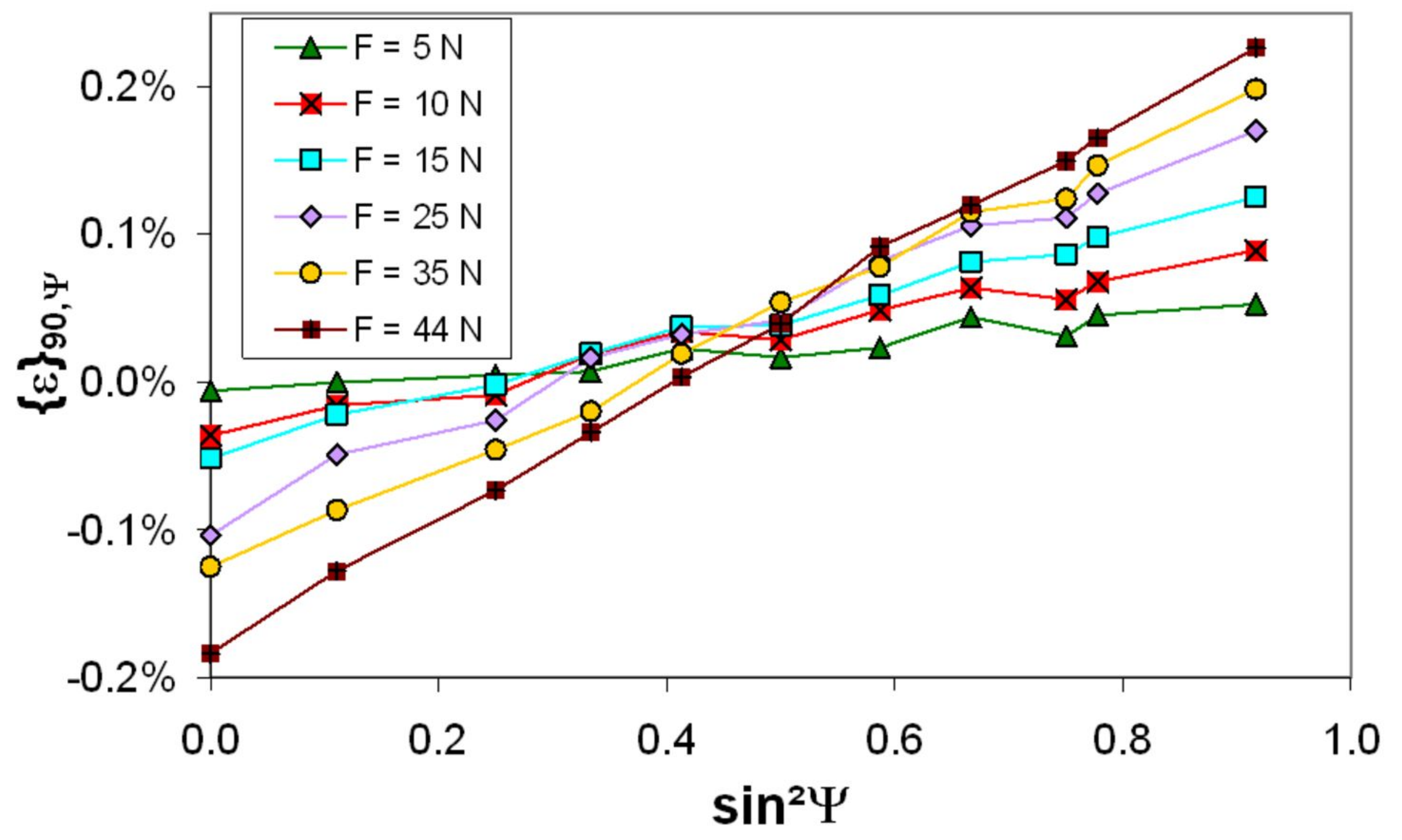




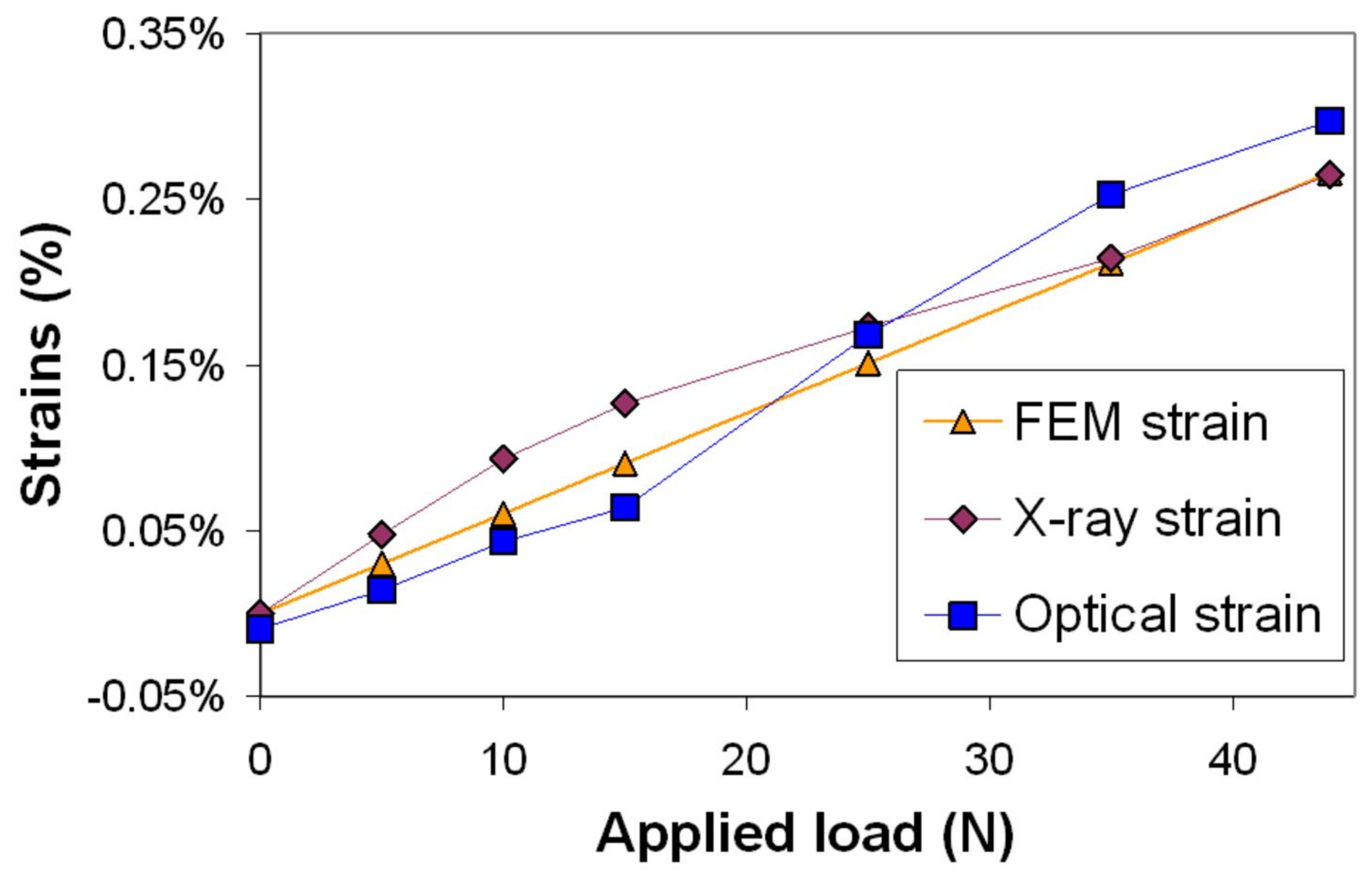




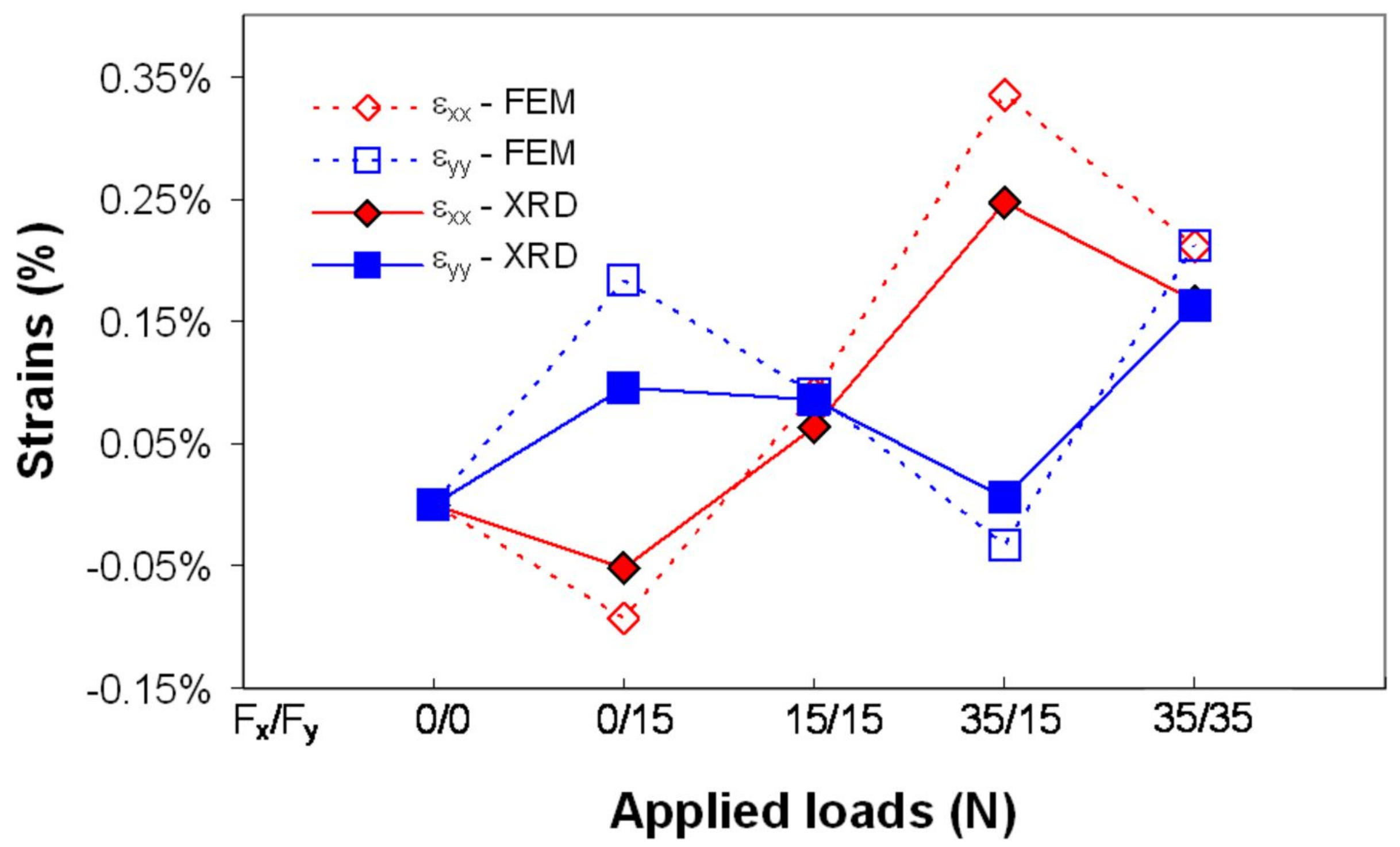

